\title{
What happens when oral tuberculosis is not treated?
}

\author{
A.E. Erbaycu11, Z. Taymaz1, F. Tuksavul11, A. Afrashi2, S.Z. Güçlü1
}

ABSTRACT: What happens when oral tuberculosis is not treated? A.E. Erbaycu, Z. Taymaz, F. Tuksavul, A. Afrashi, S.Z. Gücliu.

Pulmonary tuberculosis (TB) is the most important form of the disease, although infection may also occur by way of the intestinal tract, tonsils and skin. Oral lesions consist of persistent ulcers or granulomatous masses.

A 50 year old man had been diagnosed "necrotising granulomatous inflammation" following a biopsy of a lesion on lower lip, 21 months before at a medical centre. A chest-X-ray had not been performed and he had not been given any advise in respect of treatment.

He was admitted to the hospital with cough, sputum, weakness, weight loss and lesions on his lower lip. In radiology, it was detected that he had supraclavicular, sub- mental, cervical, mediastinal lymphadenopathies, pulmonary infiltrations with cavities, thickening and roughness on left oropharengial tonsil, thickenning on inner parts of larynx and bilateral surrenal thickening.

The biopsy of lesions on larynx, tonsil and epiglottis revealed "necrotising granulomatous inflammation" and histopathology supported TB infection. Sputum acid-fast bacilli was positive and culture was positive for Mycobacterium tuberculosis complex. Two months of combination treatment resulted in a gradual relief of the symptoms, radiological response, disappearing of neck swelling and healing of lesions on lip, tonsil and larynx.

Although unusual oral cavity manifestations of TB are rare, clinicians should be aware of possible occurrance. Monaldi Arch Chest Dis 2007; 67: 2, 116-118.

Keywords: Pulmonary tuberculosis, oral tuberculosis, lip, tonsil, larynx, epiglottis.

1 Department of Chest Diseases and Tuberculosis,

2 Department Of Otorhinolaryngology, İmir Training of Research Hospital for Thoracic Medicine and Surgery, Izmir, Turkey.

Correspondence: Dr Ahmet Emin Erbaycu, İzmir Göğ̈̈s Hastalıkları ve Cerrahisi, Eğitim ve Araştırma Hastanesi, Yenişehir, İzir. 35110, Turkey; e-mail: drerbaycu@yahoo.com

With the increasing number of tuberculosis (TB) cases, unusual forms of the disease in the oral cavity are more likely to occur and be misdiagnosed [1].

Oral manifestations of tuberculosis are extremely rare. In terminal stages of the disease, however, selfinoculation may occur from the patient's sputum. Oral lesions consist of persistent ulcers or granulomatous masses. Microscopic sections reveal an ulcer, the connective tissues under which show circumscribed nodules of epitheloid cells and giant cells [2]. Oral TB is occasionally seen in immunocompetent persons. They are usually elderly men in whom pulmonary TB has progressed unrecognised or who have neglected treatment [3]. However, patients with non-healing oral lesions or papillomatous masses in the oral mucosa should be screened for the presence of pulmonary TB [4].

This is a presentation of a case diagnosed with tuberculosis disease at multiple localisations, with his interesting history and cause of delayed diagnosis and treatment.

\section{Case Report}

A 50 year old man had been admitted to a medical centre with a swelling on his neck and a lesion on lower lip, 21 months before coming to our at- tention. Detecting cervical lymphadenopathy on palpation and "necrotising granulomatous inflammation" on biopsy of lip lesion, he had not been given any advice concerning possible treatment. $\mathrm{He}$ had been admitted to another medical centre with same complaints, twelve months ago. After the confirmation of "necrotising granulomatous inflammation" and "granulomatous cheilitis" on lip biopsy, he again had not been advised of any treatment option. In both centres, chest-X-rays had not been performed.

Five months before, he began to feel slightly ill because of swelling on his neck and submental area and white and red lesions on his lip had enlarged. When he was undergoing a surgery of his multinodulary goitre, pre-operative chest radiography revealed pulmonary lesions. He was directed to our clinic without any surgery.

He was suffering from cough, sputum, weakness, weight loss and enlarged lesions on his lower lip. He has no history of any other diseases or contact with tuberculosis patient. Both his father and mother had been suffering from hypertension.

His vital signs were normal without fever. Enlarged, protuberant and painful lesion including ulcer, hyperemia and red-white areas was seen on inner part of the lower lip (figure 1). Palpation revealed goitre and lymphadenopathies; left sub- 


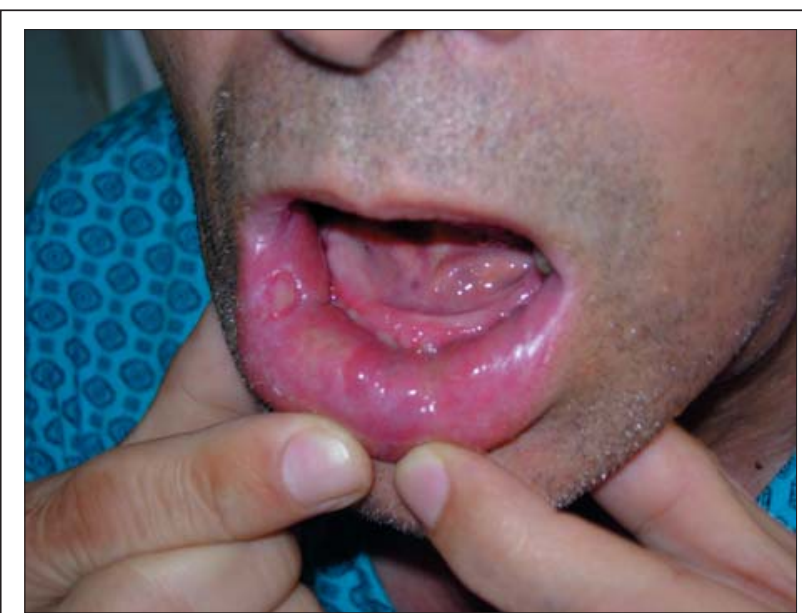

Fig. 1. - Protuberant and painful lesion on the lower lip.

mental $3 \times 3 \mathrm{~cm}$, right submental $3 \times 2 \mathrm{~cm}$ and $2 \times 2$ $\mathrm{cm}$, right supraclavicular $1 \mathrm{x} 1 \mathrm{~cm}$. With the exception of inspiratory rales, respiratory and other system physical examinations were normal.

There were bilateral cavity and reticulonodulary density in chest-X-ray. Mediastinal lymphadenopathy with $1 \mathrm{~cm}$ size, bilateral apical cavities, perbronchial infiltrations and tree-in-bud sign were detected in thorax computed tomography (CT) (figure 2).

A cervical CT revealed multiple lymphadenopathies, thickening and roughness on the left oropharengial tonsil, and also thickening on inner parts of larynx (figure 3). Bilateral surrenal thickening resembling metastatic involvement was reported in the abdominal CT.

Blood tests were as follows: erythrocyte sedimentation rate: $84 \mathrm{~mm} /$ hour, leukocyte: $8.600 / \mathrm{mm}^{3}$, neutrophils: $74.9 \%$, haemoglobin: $11.4 \mathrm{gr} / \mathrm{dL}$, platelets: $411000 / \mathrm{mm}^{3}$, free T3: $2.3 \mathrm{pg} / \mathrm{ml}(2.0-$ 4.9), free T4: $1.13 \mathrm{pg} / \mathrm{ml}(0.7-1.7)$, TSH: $1.57 \mathrm{pg} / \mathrm{ml}$ (0.25-5.0), HbsaAg, Anti HCV, Anti-HIV: negative, AntiHBs: positive (> 250), C3: $157 \mathrm{mg} / \mathrm{dl}, \mathrm{C} 4: 35.7$ mg/dl, IgA: $321 \mathrm{mg} / \mathrm{dl}$, IgM: $99.2 \mathrm{mg} / \mathrm{dl}, \mathrm{IgG}: 1380$ mg/dl IgE: 8 U/L. Routine blood biochemical tests were normal.

A tuberculin test was measured $22 \mathrm{~mm} / 72$ hours. There were increased erythrocyte in urine microscopy. Urine AFB was negative in direct mi-

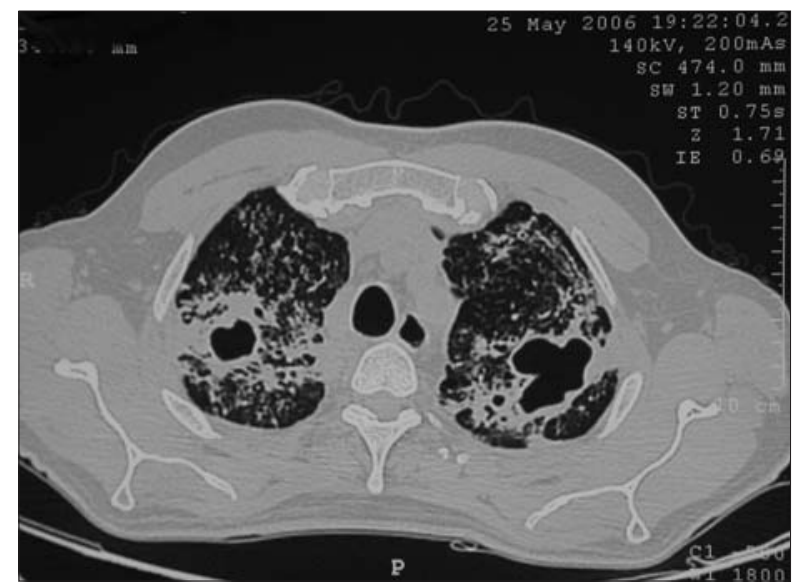

Fig. 2. - Bilateral cavity and reticulonodulary density on thorax CT. croscopy. No endobronchial lesion was seen on bronchoscopy.

During the laryngoschopy, a mass on left tonsil and thickenning on the larynx wall was detected. Biopsy of lesions on larynx, tonsil and epiglottis revealed "necrotising granulomatous inflammation" and histopathology supportted tuberculosis infection.

Sputum AFB in homogenisation was found positive. Lowenstein culture was positive for $M y$ cobacterium tuberculosis complex and the bacillus was sensitive to tuberculosis drugs.

A combination treatment containing isoniaside $300 \mathrm{mg}$, rifampicin $600 \mathrm{mg}$, ethambutol $1250 \mathrm{mg}$ and morfozinamide $2000 \mathrm{mg}$ daily was started. Two months of treatment resulted in a gradual relief of the symptoms, radiological response, disappearing of neck swelling and healing of lesions on lip, tonsil and larynx.

\section{Discussion}

Pulmonary TB is the most important form of the disease, although infection may also occur by way of the intestinal tract, tonsils and skin. Lesions may occur at any site on the oral mucous membrane, but the tongue is most commonly affected, followed by the palate, lips, buccal mucosa, gingiva and frenula $[1,5,6]$. However, the present case was diagnosed tuberculosis on lower lip, tonsil, epiglottis and larynx without tongue involvement.

Tuberculosis on the upper airway generally has the symptomatology of a cough, weight loss, dysphagia, dysphonia [7]. The present case was not suffering from dysphagia or dysphonia though larynx involvement. His primary complaint, the lower lip lesion, had a history of twenty one months. The appearence of new symptoms, cough, sputum, weakness and weight loss five months ago, are thought as the initial symptoms of pulmonary and larynx TB as a cause of misdiagnose for lip TB.

The typical lesion of oral TB is an irregular, superficial or deep, painful ulcer which tends to increase slowly in size. It is frequently found in areas of trauma and may be mistaken clinically for a simple traumatic ulcer or even carcinoma [5]. Differential diagnosis has to be made especially with

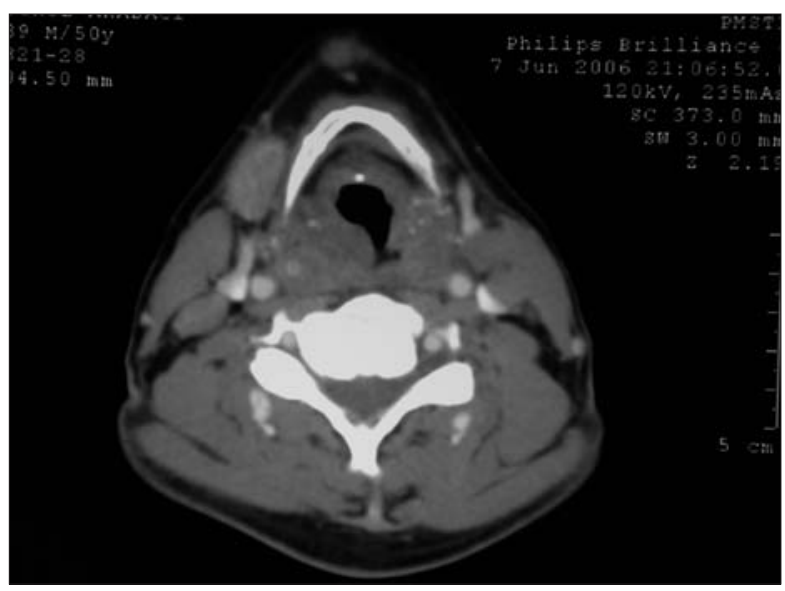

Fig. 3. - Thickening on inner parts of larynx on cervical CT. 
cancer, by biopsy [7]. Similarly, the present TB ulcer on lower lip was irregular, painful and tended to increase so slowly that patient had a history of 21 months. In this period, he had lived his life as if he had not had any disease, with a small amount of pain and discomfort on mouth.

Less than 0.1 per cent of the tuberculous patients exhibit oral lesions. They are seldom primary, but rather are secondary to a pulmonary disease. It appears most likely that the organisms are carried in the sputum and enter the mucosal tissue through a break in the surface. It is also possible that they are carried through the hematogenous route, deposited in the submucosa and subsequently to proliferate and ulcerate the overlying mucosa [5]. The patient's history of initial lesion on lower lip without any pulmonary symptom and appearence of pulmonary symptoms in the last five months led us to believe the pulmonary and larynx TB occurred secondary to undiagnosed lip TB.

The most similar case in literature belongs to Yamamoto et al., reporting tonsillar TB associated with pulmonary and laryngeal foci. The authors concluded that the possibility of tonsillar TB should be considered when unexplained enlarged tonsil is observed in patients with pulmonary TB [8].

Tuberculous lesions in the mouth do not differ microscopically from tuberculous lesions in other organs of the body. The diagnosis is rarely suspected until biopsy has shown tuberculous granulomas in the floor of the ulcer. Mycobacteria can be demonstrated in the sputum, but rarely in the oral lesion and chest radiographs show advanced infection $[3,5]$.

After the confirmation of "necrotising granulomatous inflammation" and "granulomatous cheilitis" on lip biopsy at two different centers, it was apparent that patient had not been given any diagnosis and had not been advised of any treatment option. We believe that the result of the lip biopsy was construed by the clinicians as Miescher-MelkerssonRosenthal Syndrome not as a TB disease. This syndrome is a condition of unknown etiology that causes diffuse swelling of the lips, especially the lower lip and there is no defined treatment option [5].
Tuberculosis or non-tuberculosis mycobacterial infection must be considered in patients with AIDS who develop oral ulceration with granuloma formation, microscopically [3]. Present case was HIV negative and Mycobacterium tuberculosis was identified on culture.

Standard treatment of tuberculosis infection is very successful in oral cavity TB $[3,6]$. Therefore, we planned standard combination treatment. After the initial four drugs regimen was completed, a gradual relief of the symptoms, radiological response and healing of lesions on lip, tonsil and larynx was obtained.

Although unusual oral cavity manifestations of TB are rare, clinicians should be aware of the possible occurrance. Such awareness may help to diagnose TB at an early stage and prevent complications and contaminations. When "granulomatous inflammation" is confirmed by tissue biopsy, TB should be the first suspected disease, especially in countries that still have higher TB incidence.

\section{References}

1. Sezer B, Zeytinoglu M, Tuncay Ü, Unal T. Oral mucosal ulceration: a manifestation of previously undiagnosed pulmonary tuberculosis. JADA 2004; 135: 336-40.

2. Special oral pathology. Synopsis of oral pathology. Bhaskar SN. 7th edition. The C. V. Mosby Company. Missouri 1986: 744.

3. Mucocutaneous diseases and other forms of stomatitis. Oral Disease. Cawson RA, Binnie WH, Barrett AW, Wright JM. 3rd edition. Mosby, London 2001: 13.7.

4. Miziara ID. Tuberculosis affecting the oral cavity in Brazilian HIV-infected patients. Oral Surg Oral Med Oral Pathol Oral Radiol Endod 2005; 100: 179-82.

5. Shafer WG, Hine MK, Levy BM, Tomich CE. Bacterial, viral and mycotic infections. Oral Pathology. W. B. Saunders, Tokyo, $4^{\text {th }}$ edition, 1983: 341-4.

6. Çakan A, Mutlu Z, Özsöz A, Erbaycu AE, Ünal T, Koyuncu BO. Tuberculosis of oral mucosa. Monaldi Arch Chest Dis 2001; 56: 315-7.

7. Crofton J, Horne N, Miller F. Clinical Tuberculosis Macmillan, London 1992: 117-35.

8. Yamamoto K, Iwata F, Nakamura A, et al. Tonsillar tuberculosis associated with pulmonary and laryngeal foci. Intern Med 2002; 41: 664-6.

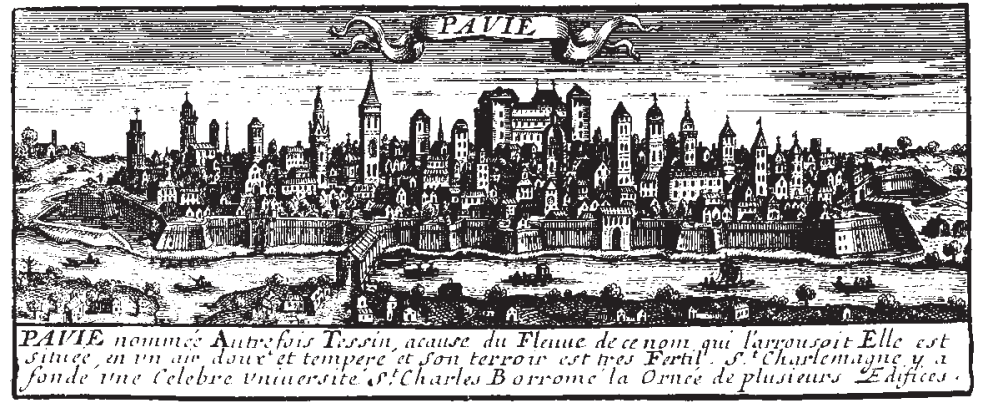

